\title{
Asertivitas Seksual dan Perilaku Seks Pranikah pada Mahasiswa
}

\author{
Natalia Tholense \& Wahyu Rahardjo \\ Fakultas Psikologi \\ Universitas Gunadarma \\ J1. Margonda Raya No 100, Depok, 16424, Jawa Barat \\ wahyu_rahardjo@yahoo.com \& christiany.suwartono@atmajaya.ac.id
}

\begin{abstract}
The purpose of this study is to examine the correlation between sexual assertiveness and premarital sexual behavior in female college students. Participants of this research is 100 female college students from Gunadarma University in Jakarta. The result shows that sexual assertiveness has negative significant correlation to premarital sexual behavior. This finding shows that women, especially female college students has to develop sexual assertiveness in order to keep away from premarital sexual behavior.
\end{abstract}

Keywords: sexual assertiveness, premarital sexual behavior, female college students

\begin{abstract}
Abstrak-Penelitian ini bertujuan untuk melihat korelasi asertivitas seksual dan perilaku seks pranikah pada mahasiswi. Partisipan penelitian ini adalah 100 orang mahasiswi dari Universitas Gunadarma di Jakarta. Hasil penelitian memperlihatkan bahwa asertivitas seksual memiliki korelasi negatif yang signifikan terhadap semua bentuk perilaku seks pranikah. Hal ini memperlihatkan bahwa asertivitas seksual penting dimiliki, terutama oleh perempuan, dalam hal ini mahasiswi, agar dapat menjaga dirinya dari stimulus yang dapat menyebabkannya terlibat dalam perilaku seks pranikah.
\end{abstract}

Kata kunci: asertivitas seksual, perilaku seks pranikah, mahasiswi

\section{PENDAHULUAN}

Perilaku seksual pranikah berkembang menjadi semakin memprihatinkan belakangan ini di Indonesia. Hal tersebut didukung oleh fakta-fakta yang ada mengenai berbagai tindakan seksual dikalangan remaja (mahasiswa baik pria maupun wanita) yang cukup mengkhawatirkan. Di dalam suatu penelitian yang melibatkan sekitar 328 mahasiswa pria mengenai perilaku seksual pranikah ditemukan bahwa perilaku seksual pranikah terjauh seperti intercourse atau hubungan seksual tergolong perilaku seks yang paling lazim dilakukan oleh mayoritas partisipan (Rahardjo, 2008). Penelitian tersebut juga menggambarkan bahwa partisipan memiliki tingkat toleransi yang cukup tinggi terhadap perilaku seksual pranikah. 
Peningkatan perilaku seksual pranikah juga tidak lepas dari peranan lingkungan. Seperti halnya masyarakat-masyarakat Asia Tenggara lainnya, standar ganda sering kali diterapkan dalam kehidupan seksualitas. Kesucian, aktivitas seksual sebelum dan di luar pernikahan adalah beberapa contoh penerapan standar ganda. Perempuan diajarkan untuk mempertahankan keperawanan, patuh, dan pasif. Laki-laki memiliki kebebasan lebih besar, aktif, perkasa dan dapat terlibat dalam hubungan seksual sebelum menikah. Sampai tingkat tertentu, keserbabolehan seksualitas masih mendapatkan toleransi bila laki-laki yang melakukannya, tetapi sangat tidak diterima bila perempuan yang melakukannya (Hidayana, 2004).

Mengacu pada perspektif psikoanalisis Sigmund Freud, laki-laki dan perempuan mengalami perkembangan identitas diri dari super-ego (perkembangan moral) yang berbeda berdasarkan asumsi bahwa organ seksual laki-laki adalah lebih superior dibandingkan dengan organ seksual perempuan. Berangkat dari perbedaan anatomi biologi yang dikukuhkan dalam konsep "anatomy is destiny", Freud menyimpulkan bahwa inferioritas perempuan dan superioritas laki-laki inilah yang selanjutnya mempengaruhi interaksi antar gender di tingkat pribadi dan sosial (Hidayana, 2004).

Meskipun berbagai anggapan mengatakan bahwa wanita adalah pihak yang inferior, lemah dan pasif dibandingkan dengan laki-laki, namun perempuan tetap memiliki kemampuan untuk bersikap tegas dalam hal seksualitas menyangkut hak-hak pribadi yang dimilikinya serta melakukan suatu hal sebagai usaha untuk mencapai kebebasan emosi (Zerubavel, 2010). Kemampuan bersikap tegas dalam hal seksualitas inilah yang kemudian disebut dengan asertivitas seksual (Zerubavel, 2010).

Asertivitas seksual adalah kemampuan seseorang bersikap tegas mempertahankan hak seksualnya untuk tidak dilecehkan dan dapat mengambil keputusan seksualnya dengan tetap memberi penghargaan atas hak orang lain dan tanpa menyakiti orang lain atau pasangannya, serta mengekspresikan dirinya secara jujur dengan cara yang tepat tanpa perasaan cemas yang mengganggu sehingga mendorong terwujudnya kesejajaran dan persamaan dalam hubungan dengan pasangannya (Falah 2009).

Komunikasi tentang penggunaan kondom juga relevan dengan asertivitas seksual (Kennedy, 2011). Hasil penelitian menunjukkan bahwa asertivitas seksual merupakan prediktor yang paling signifikan pada penggunaan kondom (Zamboni dalam Kennedy, 2011). Selain itu, penelitian yang dilakukan Zamboni menemukan bahwa seorang individu yang memiliki tingkat asertivitas seksual yang cukup tinggi, akan menunjukkan sikap positif terhadap penggunaan kondom. Penelitian ini memiliki kontribusi yang besar bagi dasar pengetahuan tentang bagaimana asertivitas seksual juga terkait dengan penggunaan kondom.

Pembahasan mengenai asertivitas seksual juga relevan dalam konteks perguruan tinggi, di mana mahasiswa baru akan mengalami penurunan status (dari status tertinggi di Sekolah Menengah Atas ke bagian bawah sebagai mahasiswa baru di Perguruan Tinggi), yang kemungkinan akan mengurangi kemampuan untuk bersikap tegas. Di dalam situasi seksual, pendapat orang lain juga dapat mempengaruhi status individu yang kemudian mungkin memiliki dampak yang sangat kuat pada kemampuan individu untuk bersikap tegas (asertif) selama tahap perkembangan di lingkungan mahasiswa (Cahill \& Phillips dalam Zerubavel, 2010). Individu yang bersikap asertif adalah individu yang mampu bersikap tegas dalam menghadapi sesuatu, tahu apa yang diinginkan tetapi juga tidak memaksakan kehendaknya (Lazarus dalam Fensterheim \& Baer, 1991) termasuk juga pada hal seksualnya. Ketidakmampuan untuk bersikap asertif sering berperan terhadap terjadinya hubungan seksual pranikah. Semakin individu mampu mempertahankan hak seksualnya, semakin individu tidak permisif terhadap perilaku seksual pranikah.

Tujuan dari penelitian ini adalah untuk melihat hubungan asertivitas seksual dan perilaku seks pranikah pada mahasiswi. Hal ini penting untuk dilakukan agar dapat diketahui keterkaitan asertivitas seksual dalam 
perilaku seks pranikah yang dilakukan mahasiswi. Riset ini diharapkan dapat membuktikan bahwa jika mahasiswi memiliki asertivitas seksual yang tinggi maka dapat menekan kecenderungan keterlibatan akan perilaku seks pranikah.

\section{METODE}

\section{Partisipan}

Uji coba dilakukan terhadap 40 orang mahasiswi Universitas Gunadarma di Jakarta. Sementara itu, partisipan yang kemudian terlibat dalam pengambilan data berjumlah 100 orang mahasiswi. Penelitian ini melibatkan mahasiswi sesuai dengan karakteristik sampel yang dibutuhkan dalam penelitian ini. Rentang usia partisipan yang terlibat dalam penelitian ini adalah antara 19-22 tahun.

\section{Desain}

Skala Asertivitas Seksual. Asertivitas seksual adalah hak serta kemampuan individu untuk menggambarkan parameter kenyamanan diri individu selama aktivitas seksual, untuk mengkomunikasikan kebutuhan sendiri atau keinginan seksual, serta kemampuan individu untuk bersikap tegas mempertahankan hak seksualnya agar tidak dilecehkan dan dapat mengambil keputusan seksualnya dengan tetap memberi penghargaan atas hak orang lain dan tanpa menyakiti orang lain atau pasangannya. Skala Asertivitas Seksual disusun berdasarkan konsep dari Jakubowski \& Lange (1978) yaitu yaitu menghormati hak-hak orang lain dan diri sendiri, berani mengemukakan pendapat secara langsung, kejujuran, memperhatikan situasi dan kondisi, dan bahasa tubuh. Ciri-ciri individu dengan perilaku asertif ini kemudian dikaitkan dengan perilaku seks pranikah agar aitem-aitem yang ada mencerminkan asertivitas seksual. Skala Asertivitas Seksual terdiri dari enam alternatif jawaban, yaitu Sangat Sesuai (SS), Sesuai (S), Agak Sesuai (AS), Agak Tidak Sesuai (ATS), Tidak Sesuai (TS), serta Sangat Tidak Sesuai (STS). Korelasi skor total pada aitem-aitem dengan daya uji beda yang baik pada skala ini bergerak antara 0.301 sampai 0.856 dengan skor reliabilitas yang ditunjukkan oleh Cronbach alpha sebesar 0.942.

Skala Perilaku Seks Pranikah. Perilaku seks pranikah adalah segala bentuk tingkah laku yang didorong oleh hasrat seksual yang dilakukan oleh individu baik dengan lawan jenis atau dengan sesama jenis. Di dalam penelitian ini perilaku seksual pranikah diukur dengan menggunakan Skala Perilaku Seksual Pranikah yang didasarkan pada bentuk-bentuk aktivitas seksual yang dikemukakan oleh Sarwono (2000) yang terdiri atas empat bentuk yaitu kissing, necking, petting, dan intercourse. Skala Perilaku Seks Pranikah terdiri dari enam alternatif jawaban, yaitu Sangat Sesuai (SS), Sesuai (S), Agak Sesuai (AS), Agak Tidak Sesuai (ATS), Tidak Sesuai (TS), serta Sangat Tidak Sesuai (STS). Korelasi skor total pada aitem-aitem dengan daya uji beda yang baik pada skala ini bergerak antara 0.356 sampai 0.845 dengan alpha sebesar 0.937 .

\section{Prosedur}

Pelaksanaan uji coba penelitian dilakukan kepada sekitar 40 orang mahasiswi universitas X di Jakarta Selatan pada pertengahan bulan Oktober 2012. Setelah dilakukan analisis terhadap daya uji beda dan reliabilitas skala, maka beberapa aitem dengan skor daya beda yang rendah dibuang. Pengambilan data penelitian kemudian dilakukan beberapa hari kemudian terhadap 100 orang mahasiswi di lokasi yang sama dari pagi hingga siang hari. Data yang masuk kemudian diolah kembali untuk dilakukan uji hipotesis. 


\section{Teknik Analisis}

Uji analisis data dilakukan dengan menggunakan uji korelasi. Uji korelasi yang pertama dilakukan antara skor total asertivitas seksual dengan skor total perilaku seks pranikah. Uji korelasi yang kedua dilakukan antara skor total asertivitas seksual dengan skor total perilaku seks pranikah pada setiap bentuk, yaitu kissing, necking, petting, dan intercourse. Untuk memperkaya hasil analisis maka dilihat perbedaan rerata empirik dan rerata hipotetik untuk masing-masing variabel.

\section{ANALISIS \& HASIL}

Korelasi antara asertivitas seksual dan perilaku seks pranikah memperlihatkan skor sebesar $r=$ $-0.595(\mathrm{p}<.00)$. Sementara itu, korelasi asertivitas seksual dengan bentuk-bentuk perilaku seks pranikah juga memperlihatkan hasil senada, yaitu dengan kissing $(r=-0.455 ; p<.00)$, necking $(r=-0.394 ; p<.00)$, petting $(r=-0.589 ; p<.00)$, dan intercourse $(r=-0.484 ; p<.00)$.

\section{DISKUSI}

Penelitian ini bertujuan untuk mengetahui hubungan antara asertivitas seksual dengan perilaku seksual pranikah pada mahasiswi. Berdasarkan hasil uji hipotesis yang telah dilakukan diketahui bahwa terdapat hubungan negatif yang sangat signifikan antara asertivitas seksual dan perilaku seksual pranikah pada mahasiswi. Ini dapat diartikan bahwa tinggi atau rendahnya asertivitas seksual berhubungan dengan tinggi atau rendahnya perilaku seksual pranikah mahasiswi tersebut.

Menurut Morokoff (dalam Kennedy, 2011), asertivitas seksual penting untuk pencapaian tujuan seksual dan perlindungan diri dari aktivitas seksual yang tidak diinginkan atau tidak aman. Asertivitas seksual juga dikaitkan dengan kemampuan wanita untuk menggambarkan parameter kenyamanan dirinya selama aktivitas seksual, untuk mengkomunikasikan kebutuhan sendiri atau keinginan seksual, hak-hak seksual, ataupun menghindari diri dari situasi seksual berisiko (Rickert, Sanghvi, \& Wiemann, 2002; Whyte, 2006; Zerubavel, 2010).

Sementara itu, Jakubowski dan Lange (1978) menyebutkan terdapat lima ciri-ciri individu dengan perilaku asertif, yaitu menghormati hak-hak orang lain dan diri sendiri, berani mengemukakan pendapat secara langsung, kejujuran, memperhatikan situasi dan kondisi, dan bahasa tubuh. Hal tersebut tentu saja penting ada dalam diri mahasiswi dalam menjalankan tugas dan tanggung jawab dalam masa perkembangannya, agar mahasiswi mampu melihat mana yang sesuai, baik dan benar bagi dirinya terkait dengan aktivitas seksual. Uraian di atas sesuai dengan hasil analisis dalam penelitian ini, di mana asertivitas seksual individu berhubungan dengan perilaku seksual pranikah pada saat tahap perkembangannya di masa dewasa awal, yang dalam hal ini dikategorikan sebagai mahasiswi.

Mahasiswi yang menjadi subjek pada penelitian ini menunjukkan bahwa mereka memiliki asertivitas seksual yang tinggi dan perilaku seksual pranikah yang rendah. Asertivitas seksual subjek pada penelitian ini berada dalam kategori tinggi. Hal ini berarti subjek mampu mempertahankan hak seksualnya dengan baik agar tidak dilecehkan oleh orang lain maupun pasangannya. Perilaku seksual pranikah subjek pada penelitian ini berada dalam kategori rendah yang artinya bahwa subjek tidak permisif untuk melakukan aktivitas seksual pranikah seperti kissing, necking, petting maupun intercourse. 
Penelitian ini juga dilakukan untuk mengetahui hubungan asertivitas seksual dan perilaku seksual pranikah beserta bentuk-bentuk dari perilaku seksual pranikah. Perilaku seksual pranikah tersebut ialah kissing, necking, petting serta intercourse.

Bedasarkan pembahasan yang sudah ada, diketahui bahwa perilaku seksual pranikah paling awal adalah bentuk kissing. Hasil penelitian ini menunjukkan bahwa perilaku seksual pranikah dalam bentuk kissing memiliki hubungan yang negatif dengan asertivitas seksual, yang berarti semakin tinggi asertivitas seksual pada subjek maka semakin rendah perilaku seksual pranikah dalam bentuk kissing pada subjek. Apabila bentuk perilaku seksual pranikah paling awal sudah memiliki hasil yang negatif, maka hampir dapat dipastikan bahwa hasil dari penelitian pada perilaku seksual pranikah paling akhir yaitu bentuk intercourse memiliki hasil yang negatif. Hasil tersebut menunjukkan bahwa perilaku seksual pranikah dalam bentuk intercourse memiliki hubungan yang negatif dengan asertivitas seksual, yang berarti semakin tinggi asertivitas seksual pada subjek maka semakin rendah perilaku seksual pranikah dalam bentuk intercourse pada subjek. Hal ini juga berarti bahwa subjek penelitian memiliki kemampuan untuk bertindak asertif dalam hal seksual terkait keempat bentuk perilaku seksual pranikah tersebut.

Hubungan yang mendasari antara asertivitas seksual dengan bentuk-bentuk perilaku seksual pranikah adalah kemampuan subjek (dalam hal ini adalah mahasiswi) berkomitmen, kemampuan subjek untuk bertindak asertif serta pengaruh situasional baik budaya maupun lingkungan (Peplau dalam Anonim, 2008). Semakin subjek memiliki kemampuan tersebut dengan demikian, bentuk-bentuk perilaku seksual pranikah juga akan semakin tidak permisif. Jelas penting artinya bagi mahasiswi untuk bisa mengembangkan asertivitas seksual walaupun cukup berat mengingat budaya patriarki cenderung dapat menyebabkan kecemasan sosial jika individu berperilaku agak bertentangan dengan kelaziman di masyarakat (Schry \& White, 2013). Hal berakibat kaum perempuan kurang bebas memperjuangkan hak-hak seksualnya (Rickert, Sanghvi, \& Wiemann, 2002).

Selain itu, dari keempat bentuk perilaku seksual pranikah yaitu; kissing, necking, petting, dan juga intercourse (Sarwono, 2000), didapatkan hasil dari sebaran data bahwa perilaku seksual pranikah bentuk kissing terdapat dikategori sedang, hal ini berarti subjek sedikit permisif untuk melakukan aktivitas seksual dalam bentuk kissing. Sedangkan perilaku seksual pranikah bentuk necking terdapat pada kategori rendah, hal ini berarti subjek tidak permisif untuk melakukan aktivitas seksual dalam bentuk necking. Perilaku seksual pranikah yang ketiga adalah petting, hasil sebaran data menunjukan bahwa perilaku seksual pranikah bentuk petting terdapat dikategori rendah, hal ini menunjukan bahwa subjek tidak permisif untuk melakukan aktivitas seksual dalam bentuk petting. Sedangkan bentuk perilaku seksual pranikah yang terakhir adalah intercourse, hasil menunjukan bahwa perilaku seksual pranikah bentuk intercourse berada pada kategori sangat rendah, hal ini berarti subjek sangat tidak permisif untuk melakukan aktivitas seksual dalam bentuk intercourse. Hal lain yang perlu diperhatikan oleh mahasiswi adalah bahwa ketidakkonsistenan asertif secara seksual memiliki konsekuensi. Individu yang sudah pernah terlibat dalam aktivitas seksual tertentu cenderung memiliki asertivitas seksual yang lebih rendah dan menjadi lebih toleran dan sulit menolak ajakan melakukan aktivitas seksual lebih lanjut (Auslander, Perfect, Succop, \& Rosenthal, 2007).

\section{SIMPULAN \& SARAN}

Asertivitas seksual sangat dibutuhkan oleh siapa pun, termasuk oleh pihak perempuan, dalam hal ini mahasiswi, untuk membantu dirinya menolak segala stimulus dari lawan jenis yang menuntun kepada 
terjadinya aktivitas seks pranikah. Keputusan penolakan dari pihak perempuan selama ini menjadi masalah karena perempuan dengan alasan-alasan tertentu cenderung takut untuk menolak atau bahkan toleran terhadap ajakan melakukan aktivitas seksual tertentu dari lawan jenisnya.

Saran yang dapat diajukan kepada partisipan penelitian adalah untuk lebih mampu mengembangkan perilaku asertif berkaitan ajakan untuk terlibat dalam aktivitas seksual. Bagi peneliti lain dapat melibatkan variabel-variabel lain yang mungkin dapat berkaitan dengan perilaku seks pranikah pada mahasiswi seperti standar ganda seksualitas, intimasi, dan hal-hal lainnya.

\section{DAFTAR PUSTAKA}

Auslander, B.A., Perfect, M.M., Succop, P.A., \& Rosenthal, S.L. (2007). Perceptions of sexual assertiveness among adolescent girls: Initiation, refusal, and use of protective behaviors. Journal of Pediatric and Adolescent Gynecology, 20, 157-162.

Falah, P.N. (2009). Hubungan antara perilaku asertif dengan perilaku seksual remaja putri. Skripsi (tidak diterbitkan). Surakarta: Fakultas Psikologi Universitas Muhammadiyah Surakarta.

Fensterheim, H., \& Baer, J. (1991). Jangan bilang "YA” bila anda akan mengatakan "TIDAK”. Jakarta: Gunung Jati.

Hidayana, I.M. (2004). Seksualitas: Teori dan realitas. Depok: Program Gender dan Seksualitas FISIP UI.

Jackubowski, P., \& Lange, A. J. (1978). Responsible assertive behavior, cognitive behavioral procedures training. Illionis: Research Press.

Kennedy, B.R. (2011). Promoting African American women and sexual assertiveness in reducing HIV/AIDS: An analytical review of the research literature. Journal of Cultural Diversity, 18, 142-149.

Rahardjo, W. (2008). Perilaku seks pranikah pada mahasiswa pria: Kaitannya dengan sikap terhadap tipe cinta eros dan ludus, dan fantasi erotis. Indigenous, 10, 3-18.

Rickert, V.I., Sanghvi, R., \& Wiemann, C.M. (2002). Is lack of sexual assertiveness among adolescent and young adult women a cause of concern? Perspective on Sexual and Reproductive Health, 34, 178-183.

Sarwono, S.W. (2000). Psikologi Remaja, Edisi 1. Jakarta: Rajawali Press.

Schry, A.R., \& White, S.W. (2013). Sexual assertiveness mediates the effect of social interaction anxiety on sexual victimization risk among college women. Behavior Therapy, 44, 125-136.

Whyte, J. (2006). Sexual assertiveness in low-income African American women: Unwanted sex, survival, and HIV risk. Journal of Community Health Nursing, 23, 235-244.

Zerubavel, N. (2010). Barriers to sexual assertiveness in college women: a focus on fear of sexual powerlessness and emotion dysregulation. Unpublished thesis. Miami University Oxford, $\mathrm{OH}$.

\section{Internet}

Anonim. (2008). Tanpa judul. http://baguspsi.blog.unair.ac.id/2008/06/05/. Diakses tanggal 25 Februari 2013. 